\title{
HRQoL assessment by SRS-30 for Chinese patients with surgery for Adolescent Idiopathic Scoliosis (AIS)
}

\author{
Bobby Kin Wah Ng${ }^{1,2}$, Wai Wang Chau ${ }^{1}$, Anna Chak Na Hui ${ }^{3}$, Po Yin Cheng ${ }^{3}$, Chau Yuet Wong ${ }^{3}$, Bin Wang ${ }^{1}$, \\ Jack Chun Yiu Cheng ${ }^{1,2}$, Tsz Ping Lam ${ }^{1,2^{*}}$ \\ From The 10th Meeting of the International Research Society of Spinal Deformities (IRSSD 2014 Sapporo) \\ Sapporo, Japan. 29 June - 2 July 2014
}

\section{Objectives}

SRS-30 as a health-related quality of life (HRQoL) questionnaire was established since 2003. Literatures from Asian countries on SRS-30 mainly derived from local adaptation and related validation studies. Reports on its use for measuring surgical outcomes were sparse, particularly in the Chinese community. We carried out a retrospective cohort study using SRS-30 to evaluate HRQoL for Chinese AIS adolescents before and after surgery.

\section{Material and methods}

One hundred and four (104) Chinese AIS patients undergoing posterior spinal fusion between 2009 and 2013 were recruited. They completed SRS-30 before hospital discharge, and post-surgery questions were asked again 6 months to 3 years after discharge through phone interview. Mean scores in different domains were calculated at 3 time points, namely at the time before surgery (pre-op), immediately after surgery (discharge), and at follow-up (follow-up). Change in scores between follow-up and discharge (change after discharge) was calculated. Genderspecifc descriptive analyses were summarized. Pearson's correlations on scores collected at the 3 time points and "change after discharge" were carried out. Effects of potential risk factors (age, pre-op maximum Cobb angle, curve correction after surgery in degrees) on mean domain scores were evaluated by linear regression models.

\section{Results}

The mean age (in years) was 17.65 (male) and 15.92 (female), and $80.8 \%$ were female. There were significant

'Department of Orthopaedics and Traumatology, The Chinese University of Hong Kong, Hong Kong

Full list of author information is available at the end of the article correlations between pre-op and discharge scores in function-activity $(\mathrm{r}=-0.47, \mathrm{p}=0.05)$ in male. In female, correlations were found between pre-op and "change after discharge" in pain $(\mathrm{r}=-0.23, \mathrm{p}=0.04)$, and satisfaction with management between pre-op and discharge $(\mathrm{r}=0.334, \mathrm{p}<0.01)$ and pre-op and "change after discharge" $(\mathrm{r}=-0.47, \mathrm{p}<0.01)$. Linear regression analysis showed that pre-op maximum Cobb angle was a significant predictor $(B=-0.027, p=0.02)$ on satisfaction with management at follow-up in male patients. Comparing the scores at "change after discharge" in male showed degree of curve correction after surgery was a significant predictor in self-image-appearance $(B=-0.159, p<0.01)$ and satisfaction with management $(B=-0.123, p<0.01)$. Pre-op maximum Cobb angle was found to be another significant predictor $(\mathrm{B}=0.052, \mathrm{p}=0.02)$ on self-imageappearance in male. In female patients, degree of curve correction after surgery was a significant predictor $(\mathrm{B}=0.045, \mathrm{p}=0.04)$ on function-activity at "change after discharge".

\section{Conclusions}

Gender differences were found of which female patients demonstrated correlations on pain and satisfaction with management before and after surgery, and male patients on function-activity. Degree of curve correction after surgery and pre-op maximum Cobb angle were significant predictors on function-activity, self-image-appearance, and satisfaction with management in AIS patients.

\section{Authors' details}

'Department of Orthopaedics and Traumatology, The Chinese University of Hong Kong, Hong Kong. ${ }^{2}$ Joint Scoliosis Research Center of the Chinese 
Published: 19 January 2015

doi:10.1186/1748-7161-10-S1-P31

Cite this article as: $\mathrm{Ng}$ et al:: HRQoL assessment by SRS-30 for Chinese patients with surgery for Adolescent Idiopathic Scoliosis (AIS). Scoliosis 2015 10(Suppl 1):P31.

Submit your next manuscript to BioMed Central and take full advantage of:

- Convenient online submission

- Thorough peer review

- No space constraints or color figure charges

- Immediate publication on acceptance

- Inclusion in PubMed, CAS, Scopus and Google Scholar

- Research which is freely available for redistribution 